\title{
Evaluation of the Integrated Community- Based Home Care model
}

\author{
LR Uys, D Soc Sc (Nursing),School of Nursing, University of Natal
}

\section{Abstract}

In 1999-2000 the Integrated Community-Based Home Care model for the care of people with AIDS in communities were implemented in seven sites across the country. The post-implementation evaluation showed that most respondents felt that the model could be replicated if a functioning and informed network including all partners, and a strong management team were in place. The effects of the project were mainly positive for all stakeholders (hospice, clinic, hospital, PWA and their carers, professionals and other community members). Hospitals and community-based services became more aware of and involved in the needs of PWA and felt that the model enabled them to address these needs. PWA and their carers felt supported and respected.

\section{Opsomming}

In 1999-2000 is die Geintegreerde Gemeenskapsgebaseerde Tuissorg Model vir die versorging van mense met VIGS in die gemeenskap in sewe plekke in die land geimplementeer. Die evaluasie na implementering het getoon dat die meeste van die respondente gevoel het dat die model meer algemeen gebruik kon word indien ' $n$ funksionerende en ingeligte netwerk van alle vennote en ' $n$ sterk bestuurspan teenwoordig was. Die effek van die projek op al die belanghebbendes (hospies, kliniek, hospitaal, PWA en hul versorgers, professionele persone en ander gemeenskapslede) was hoofsaaklik positief. Dienste het meer bewus geword van die behoeftes van PWA en het beter daarin geslaag om hierdie behoeftes aan te spreek. PWA en hul versorgers het gevoel hul word gerespekteer, gehelp en ondersteun.

\section{Acknowledgement}

The financial assistance for the study from the Department of Health is aknowledged. Thank you very much to the staff of all the sites, as well as the PWA and their carers. The registered nurse supervisors need special mention: Yvonne Banks, Francisca Dladla, Virginia Dunjwa, Sandy de Villiers, Vanessa Murray, Elizabeth Swartz, Ivy Apolis and Lesley Lawson.

\section{Introduction}

Over the last ten years numerous home-based care projects focused on the needs of People Living With AIDS (PWAs) developed in South Africa as the AIDS epidemic spread. It is estimated that South Africa currently has a $22.4 \%$ HIV prevalence (Department of Health, 2000), making it imperative that realistic plans for the care of people with AIDS (PWA) be put in place.

While some of these projects are still in their infancy, some have matured to the level where evaluation has become possible. It is essential that such evaluation be done, for a number of reasons:

1. Most of these projects were started by Non-Govern mental Organizations (NGOs) which are dependant on donor funding for their existence. It is important that evaluation data be available to such donors, so that scarce donor funding goes to projects which in deed serve the needs of the population.

2. Since many such projects are only just starting, it is also important for planners of such services to study models already implemented, and evaluation of such models. This may enable new projects to avoid mistakes made by others.

3. It is also important for PWA organizations to have access to evaluation studies, which enable them to support their efforts for improved services.

One such effort to establish home-based care was developed by the SA Hospice Association. They developed the Integrated Community-Based Home Care model (ICHC) at the South Coast Hospice in 1997-98 (Louden, 1999) and disseminated it to seven other hospice sites across five provinces during 1999 2000 .

This article describes the post-implementation evaluation of this model. The study was undertaken for the Department of Health, which was interested in making policy decisions with regard to home-based care for PWA, and for the South African Hospice Association, who wanted to know how they could improve their performance. It was therefore appropriate to use Patton's Utilization-focused Evaluation approach. In this approach the evaluator works with the primary intended information users to identify which questions they deem to be critical for their use (Patton, 1978). The primary users are also involved in making decisions with regard to research methods, and involved in interpreting data and making recommendations. This process is intended to ensure that money and time is not wasted on research which does not get used.

Schrettenbrunner and Harpham (1993:129) identified impact evaluation as the most favoured type of evaluation study in Primary Health Care Projects. Impact evaluation refers to the changes in morbidity, mortality, nutritional status or fertility. They also point out a number of problems in relation to evalu- 
ating impact in such projects. A number of these are relevant for the current study. Firstly, impact evaluation requires that impact evaluation takes place a significant period after implementation. In the case of Home-based care the Department of Health needed urgent answers to their question, since they were faced with a growing problem. Since implementation alone would take at least one year, they could not wait for a longer term impact evaluation. Secondly, impact evaluation requires adequate control groups. In this study seven sites where homebased care was implemented were studied, but no sites where no such care existed. Such a study would have been very difficult and expensive, since PWAs are not identified in such communities, and the researcher would therefore not have had access to such homes.

They also raise the problem of impact indicators. This was a particular problem in this study, since the project could not be expected to reduce mortality. Although it could be expected to have an impact on hospitalization rates and bed occupancy by PWA, the lack of universal testing made it impossible to measure this. The evaluation therefore had to focus on outputs and outcomes. According to the definitions by Schrettenbrunner and Harpham (1993: 128), an output is the product of the system, such as staff time spent, drugs available to clients; while outcomes are the effects and coverage of the outputs.

\section{The model}

Although home-based care is seen as "the day-to-day care (medical, psychological and material) that a person with AIDS receives in his or her own community" (McDonnell, Brennan, Burnham and Tarantola, 1994: 430), it is also recognized that it cannot exist without the support from other providers in a continuum of care.

This home-care model which aims to provide a continuum of care which includes counseling and support of well people with AIDS (PWA) while placing emphasis on palliative and terminal care. It specifically aims at developing a care system which is effective and sustainable in the context of a developing country.

According to the International Hospice Institute and College (IHIC) "Palliative care is comprehensive care of people with active progressive far advanced disease for whom the prognosis is limited and the focus of care is the quality of life" (in Doyle, Hanks and Macdonald, 1993: 128). It can be argued that in developing countries and particularly underprivileged rural communities, the majority of well PWA qualify for palliative care from the time of diagnosis, in that their prognosis is already limited and the focus of care revolves around improving their quality of life.

Terminal care refers to end of life care and it is the objective of this model to enable most PWA to die at home. This can be done if their families can be supported in the care they give, and they understand the illness and its prognosis.

The program consists of the following: (see figure one)

a) A number of partners collaborate to provide a continuum of services, which enhances holistic care of the PWA, support for the caregivers and families, and increase understanding of the community. These include at least a home care team, a hospice, a clinic and a hospital.

b) Counseling is an essential part of the provision. Despite the palliative care focus, community caregivers have been equipped with pre- and post-test counseling skills which they frequently use in both the hospital and home-care setting. Counseling is seen as an ongoing process which commences before testing, and continues through into bereavement. It is ideally done by one person, to provide consistent support.

c) An integral part of the ICHC model is the involvement of and collaboration between Hospital-Hospice-Primary Health Care Clinic (PHC) who, together with the community, take ownership of the program.

d) Hospital-Hospice-PHC professional staff train, supervise and support jointly selected community caregivers (CCG) who in turn provide care, information, supervision and support to the PWA, their families and the micro-community in which they live. The registered nurse who directly supervises the CCGs is referred to as the supervisory registered nurse (SRN).

PALLIATIVE CARE FOR PWA: INTEGRATED COMMUNITY-BASED HOME CARE (ICHC)

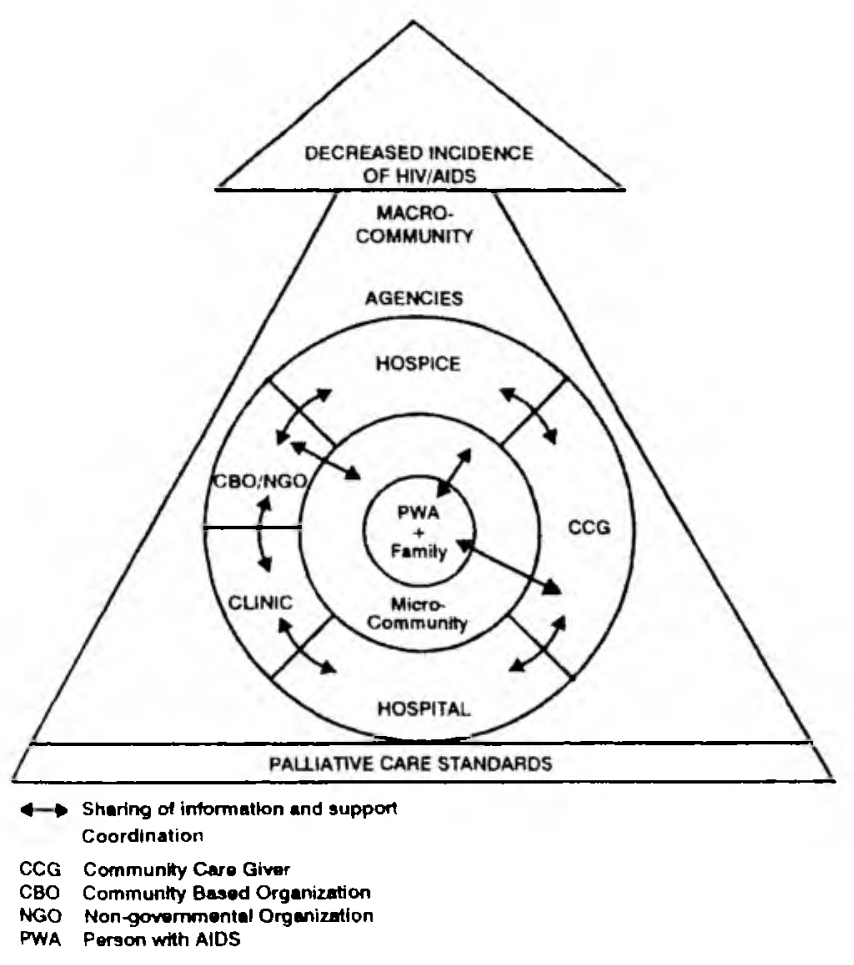

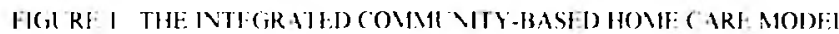
(IC) 
e) The CCG are trained for three months, of which six weeks are theory, and six weeks are practica in hospices, clinics and homes. The focus of the training is basic nursing skills, counseling, holistic palliative care and HIV/AIDS.

\section{The study}

During 2000 an evaluation study was done which included seven sites where this model had been implemented. The implementation was firstly monitored, and only when there was certainty that the model had been successfully implemented, was post-implementation done (Schrettenbrunner and Harpham, 1993). The sites included one metropolitan site, two urban sites, two peri-urban sites and two rural sites. Duration of implementation ranged from three years to three months.

The evaluation addressed a number of questions which dealt both with continuous assessment during implementation, and with post-implementation assessment. The post-implementation questions were:

1 . What were the perceptions of professionals on the replicability of the model?

2. How satisfied were PWA, their carers and other stakeholders with the model?

3. What was the impact of the model on the different partners? The post-implementation data was collected both in a focus group interview, and through one-page questionnaires that used both a rating scale for five items and open-ended questions. A total of 36 people completed the questionnaires, and between six and twelve people attended each of the seven focus groups. On average the majority of these professionals represented the hospice (14) or the clinics (13), while hospitals (4) and other agencies working with PWA (3) were represented in smaller numbers.

Data was analyzed using the three research questions as a template (Crabtree and William, 1992). The data was seen as trustworthy since it not only came from different sources within each site, but also from seven different sites. Furthermore, the process of data collection spread over months, and this allowed the researcher to discuss analysis of earlier data with respondents during later phases of data collection.

\section{Results}

\section{Replicability of the model}

Of the 36 people who completed the questionnaires, only two felt that it would be a problem to replicate this model elsewhere. People often qualified their statement by saying that it was not necessary for Hospice to be the NGO involved. In settings where there were no hospices, or where the hospice did not have the capacity to manage this model, other appropriate NGO's could be used. The hospice focus on quality of care was however, often mentioned as a particular strength which was brought to the model.

When professionals were asked what should be in place for this model to work, the following aspects were mentioned most often:

A functioning and informed network including all partners: Professionals felt that unless enough time is spent initially on informing everybody, and getting them involved, the model could work. In some settings this took much time, and is only now, after almost 12 months, beginning to get together. Re- spondents mentioned commitment to a shared vision repeatedly, underlying the fact that cooperation is not always easy. The crucial role of referral in this network was highlighted by a doctor in one of the sites as follows: "While the main site of service delivery is the NGO, the client usually enters the system at the clinic or the hospital. Without a very well functioning link between these two (clinic and hospital) and the NGO, the whole thing falls apart"

\section{A strong management team to pull everything together:}

In order to involve the partners and use all the available resources, there has to be a strong central organizer. In all the sites this was supplied by Hospice. They had the task of involving other roleplayers and keeping them involved, and ensuring that the basic resources were in place. Clearly this requirement is not available in each community, and this has to influence the replicability of the model.

Another aspect which throws light on the issue of replicability, is the question of how the model had to be adapted to make it work in different settings

\section{The outcomes for different stakeholders}

The effects of the model on the different service agencies were explored.

\section{Effects for hospice}

The following were mentioned with regard to the impact of implementing this model on the seven hospices:

1.The workload increased, with increasing stress on staff. Supervisory duties, data collection and getting social grants for clients, were more demanding than expected. Furthermore, there are increasing demands that the service be expanded to areas not yet served, as well as for community education and CCG training.

2. The hospice has become more visible in the community, with clinics and hospitals and with Department of Health. This has increased interest in hospice and support for their work. The networking skills of staff have improved and they have become more aware of community resources. They became an active partner in the network of health care delivery in a new way, with solid links between hospice, clinics and hospitals. One worker, however, also commented that the greater visibility lead to people "thinking they can dump everything on us". 3. The work has been rewarding, and getting the project off the ground against many odds was a victory. Working with CCGs for the first time was an eye-opener to some hospice staff. Their dedication and ability was mentioned. It was felt that the project "unleashed a dormant resource in the community". Another nurse said "It has been wonderful to see the difference it has made to families' lives, seeing the improvements in clients, improvements in strength and in wounds. We have been able to really touch the problem."

4. Admissions to hospice decreased as people accepted the fact that they could stay at home and die at home with support from the CCGs.

5. The hospice movement has become more "HIV/AIDS friendly". It used to be an organization mainly focused on cancer care, and with limited vision for HIV/AIDS. This project has changed that. 
6. Greater awareness of HIV/AIDS amongst all staff has been created about their problems, especially poverty and the orphan problem. This led hospices to get involved in poverty alleviation, something they had never done before. It has also led to new skills being learnt, such as counselling of children.

\section{Effects for clinics}

The day hospitals and clinics felt the following effects on themselves and their service:

1. They became more aware of the problem. and more involved in tackling it. They felt that the community also became more aware, and started using the clinic as a resource. Their communication with communities (schools, churches and traditional healers were mentioned) became more frequent and open. Many of them also started doing voluntary work, and assisting others who were working on a voluntary basis.

2. For many it was the first time they were involved in training and in working closely with CCGs. They appreciated the quality of care given, and enjoyed being part of it. They appreciated having this resource available to refer patients to The have been a rescue to $u s$, were the words of one clinic nurse. 3. In some clinics the CCGs assisted with counselling and with community education such as World AIDS Day, and this was much appreciated.

4. Fewer clients come to the clinics "just for talking". They get emotional support and education from the CCGs, so that they just use the clinics for symptom control.

5 . They are seeing more people coming for voluntary testing.

\section{Effects on hospitals}

As already mentioned, it was difficult to engage hospitals in the projects. In only three sites were representatives from hospitals part of the focus groups. The following were mentioned:

1. When they discharge a patient, they now know that there is care available. They see the home-based care as "completing the continuum of care", and doing what the hospital cannot do. They see this as a way of positively involving the family in care-giving.

2. They have also seen an increase in voluntary testing, and a decrease in congestion of hospital beds. This hospital, one of the two which is fully involved, testified that PWAs are now only admitted for good reasons.

3. One hospital saw a positive change in the attitude of staff as a result of their contact with hospice staff and CCGs. They saw a different approach to patient care and it changed their attitudes.

4. Palliative care improved in the two hospitals that became fully involved in the project, urban site (4) and rural site (2). For instance, in the rural hospitals of site 2 this topic was included in inservice programmes, syringe driver were obtained, and reference texts were bought for staff to use.

All professionals were also asked about the positive spinoffs of the implementation of the model. By this was meant things which were not directly planned for, but which happened in any case.

Income generation and poverty alleviation: As workers became conscious of the depth of poverty of their clients, so the hospices became involved in trying to do something about it. For instance, at the metro site (1) they were do- nated goods by a church and are selling these items from their premises. They are also planning a large garden on their grounds. In one rural site (3) the CCGs hand out seeds, and all PWAs are encouraged to start their own gardens. This has been amazingly successful, even in informal settlements where space is very limited, and one client has her garden in an old baby bath.

Increased cooperation between different health services: Although the model is built on cooperation, none of the staff was really aware of how little they knew about one another, and how much they could offer one another. Hospital staff became aware of their lack of knowledge and skill in terms of palliative care. Hospice became more involved with communities, and involved community leaders more in their work. The working relationships were cemented over the months, with the monthly meetings providing a forum for contact and communication. The network did not remain static, but increased in size, with general practitioners, traditional healers and service groups joining in.

Making problems visible: Just as the problem of poverty became visible, so the problem of orphans jumped the workers in the face. It is interesting that these two problems were not even mentioned in the model. The new awareness was something all partners mentioned as a positive spin-off.

Leading to other projects: In many of the sites the initial project has led to others. In one rural site (3), one professional testified to a sudden increase in community projects. In others new government tenders, funding proposals for services and income generation projects have commenced,

\section{Satisfaction with the model}

The satisfaction with the model will be dealt with by discussing the opinions of ambulant PWA, bedridden PWA and their care givers, care givers in general, and professionals.

\section{Ambulant PWA}

These were seen in focus groups in four sites, and by visiting in three. They were all positive about the project. They described the following as the things they liked (benefits) about the CCG and the support groups they attended:

- Information is given. "They help us to accept that we have this thing" "They make us stronger by information, telling us this is not the end".

- $\quad$ PWA receive care in a positive atmosphere. "The outstanding point is that they give me security. I now have mothers. I am an orphan. But they make me feel like I belong, like I am not alone".

- CCGs intervene on behalf of PWA with family, neighbours, employers.

- CCGs assist with the many general problems PWA have, such as getting documents so that they can get grants, food, housing.

- $\quad$ CCGs do health assessment and direct PWA to the appropriate health service, e.g. specialized skin clinic at hospital where they can get the correct 
medication, instead of just going to the nearest clinic.

They go with PWA to a health service to assist them through the process.

- When they get sick with OI, they are visited and assisted. A number of them said that they had been bedridden before the CCGs came and got them better.

In some settings PWA are equally positive about the care they receive at clinics and hospitals, but, that is not the universal satisfaction for these components that one gets for CCGs.

Their main complaints involve the attitudes of staff. PWA said that it looked as though nurses and doctors talked about PWA to each other. They made comments such as "Don't bother us, we cannot help you". They left PWA waiting for longer periods than other clients.

\section{Example: Woman PWA:}

Just after I got my baby I felt these glands and I went for tests. Two weeks later they told me. I was very shocked. How am I going to tell my people. After two months I went back to repeat the test. Perhaps it was wrong. No, it is positive. It is then that I met Patricia* (CCG). She talked to me and we told my people. Now I am satisfied.

I come to this support group regularly. They explain what I don't understand. You don't know whether this illness is slow or fast. If nobody tells you, you sit and worry alone at home. Here they talk, give you love, and then you feel better. They have a positive attitude. We become like sisters and brothers.

* All names used in this article are pseudonyms.

Another major problem is not getting the help needed. One PWA said the following: I was supposed to get food, but I only got it once. Then they said I should apply again. I could not walk at that time, but they said, apply again. You don't get the help you expected. They tell you we don't have this, don't have that. It is useless. You go and sit there the whole day, and then 4'clock they tell you to come back tomorrow. Actually, by 3.30 they already sit down. Another woman said: I cannot walk long distances. I cannot get to the clinic. The pills are free, but I have to pay to get to the clinic. If I get money, it is too late for the pillsthey are all gone. When neighbours go for the pills, the clinic refuses. They even refuse to give my pills to the CCG to bring to me.

When they were asked what was missing, or what else they needed, the following were mentioned:

Employment: This group feels their own need for employment and income very strongly. Repeatedly PWA said that there was nobody in their home who was working or earning an income. They still felt strong enough to work, but there was no work available.

Enriching the support groups: PWA felt that if the sup- port groups could be held in places where there were more sport or recreation facilities, this could help them. It would create opportunities to interact with health people, and keep their brains and bodies working.

The opportunity to be involved: Many PWA said that they should be more involved in telling others about HIV/AIDS. One man said "A thing that bites you, you can describe to others". Even so, some of them have had the experience that people do not believe they are HIV Positive, because they do not look ill. They feel that they should be paid something for such talks, since this is their "work". One woman said that she wanted to start a school for PWA, so that they could get focused. She believes it helped her a lot to become busy and focused. Another felt that they could be trained to nurse each other.

\section{Bedridden PWA and their carers}

In this section the comments of all carers will be dealt with. The affected relatives of some of the carers interviewed had already died, while others were still alive.

Again, the carers were universally positive about the CCG's service. They had few or no comments about clinics or hospitals.

The aspects they appreciated most were:

Medication, food and equipment: To this group the aspect most often mentioned is the things the CCG bring to the carer, such as medication, gloves, linen savers and food.

Assistance with care: The carers appreciated the assistance they got with care. "They were so punctual. Every morning they came and washed him and spoke with us". Another woman told how a patient got very ill over a weekend. The CCG came and took her to the clinic and came back with her and took care of all the household chores. The assistance CCGs offer also involves teaching the family to take care of the patients. One woman, who is taking care of her brother, said: "We were so scared to get close to him. But now when Patsy came, she showed us it was so easy. You just use gloves sometimes, but touching is no problem". Another mentioned the help it was that the CCG would go shopping for her.

Transport: In many settings the CCGs assist families with transport. They take patients to clinics or hospitals, and bring them back afterwards. Without this assistance, many families have to push the patient on a wheelbarrow, since they do not have money for transport.

Their presence and attitude: Many carers and PWA mention the reassurance of knowing somebody is interested, and will be visiting you. One woman said: "She (the CCG) is such a caring person. Even if she comes without any pills or anything, I feel better. They assist with advice about the little problems which crop up in the care of such a patient, since most of them have no experience of caring for a PWA. The carers also appreciated the fact that the contact did not abruptly stop on the death of the patient. The CCG assisted with arranging the funeral, often attended it, and continued to assist with orphans left positive. 


\section{Introducing a carer:}

I am Sanel's mother. Sanel already had this illness in 1997. Then I was looking after my husband, who was dying of cancer. A community health worker came to see me about his care, and I told her about Sanel. She referred me to the CCGs.

The care for Sanel was very good. Sister $B$ was always there. What I did not know, they could tell me. They helped wash her and so on. She had a very special relationship with Sister $B$. She really felt the support. They really helped me a lot. I could keep on working longer because they were here. But at the end of January I had to give up my work to look after her. She died on the $20^{\text {th }}$ March. CCG $E$ washed her that morning. Later that morning she did not look good. She was so tired. I called Sister $B$ and she gave her something to make her comfortable. She died in the afternoon. Very quiet.

\section{Other community members}

In three sites different community members also came forward to be interviewed: a few members of the street committees in one urban site (4), a community liaison person in one rural site (3), and two pastors in the metro site (1).

They all made positive comments about the effects on the community. They spoke of increased awareness, increased skill in dealing with the disease and those suffering from it, and more openness.

\section{The professionals}

The professionals were also positive about the project. They felt that the model was user friendly, relevant and easy to understand and implement. It promoted acceptance of the illness by the patient, family and friends, and also by the community, and thereby decreased discrimination and stigma. It also ensured continuity of care and empowered families to look after their family members at home until death. It also equipped the community, in the form of the CCGs to deal with the problem of HIV/AIDS. The commitment of individuals was often mentioned, e.g. the RNS or the CCGs. In the questionnaire survey $50 \%$ felt that family support were adequate and $36 \%$ felt it was excellent. Similarly, only $6 \%$ ( 2 people) felt that the support of PWAs and their incorporation into the care system were problematic or poor.

\section{Discussion and recommendations}

The discussion and recommendations will be done in the form of answering the research questions addresssed by the research.

\section{How replicable is the ICHC model ?}

There seems to be general consensus that the model can be replicated if the two essentials are in place, namely a functioning and informed and committed network of all partners, and a strong management team to pull it all together. It would seem that the involvement of an NGO with a proven record for man- agement and quality of work is essential, since the formal health sector partners find it difficult to reach out into the community.

In the HIV/AIDS sirategic plan for South Africa (2000:28) one of the strategies in the priority to "provide adequate treatment, care and support services in communities" is to "promote the establishment of intersectoral task teams at community level to drive home- and community-based care". This statement leads one to think that the necessity of having a lead NGO to take the overall responsibility to manage the process is inadequately recognized. Mobilizing, coordinating and strengthening the capacity of communities to deal with the care of PWA is a difficult task. In each site the management and dedication of the NGO played a major role in orchestrating an adequate response to the threat.

It is interesting to note that the demand from a number of informants that the model needs a committed network with a shared vision, corresponds word-for-word to the list of essentials listed by Thompson and Stachenko (1994) for a successful partnership. They say that initial face-to-face contact should be followed by regular on-going communication between representatives of the partners, and on-going communication within each partner organization. This has proved to be true in this project. Another author (Editor, 1994) also mentioned the need for leadership as one of the seven essentials for intersectoral partnerships.

The question arises whether the hospital could provide the over-all leadership instead of the NGO. This would seem to have a number of problems. Firstly, hospitals do not traditionally have expertise with regard to running home-based care programmes, which the Hospice, as NGO has. McDonnell et al (1994: 430) pointed out that one of the most common problems with home-based care for PWA is " the tendency to focus almost exclusively on the health system rather than aiming to strengthen the community in which the person spends the majority of his or her time". Furthermore, it cannot be denied that inpatient care will always take precedence with hospital staff over anything that goes on in the community. This is not the care with a NGO based in the community. From the experience of this project, it is also not easy to engage hospitals in such projects, though this might be different if they were in charge. There are examples of such projects, such as the one run by the Church of Scotland Hospital in KwaZulu-Natal. It would therefore seem that an NGO with a track record of providing home-based care is the lead partner of choice, but that hospitals can be used if such an NGO is not available.

\section{How satisfied were PWAs, their carers and other stakeholders with the model?}

PWAs:

The PWAs were universally satisfied with the care they received from CCGs, but less so with clinics and hospitals. With regard to CCGs they listed the type of care received, the attitude of workers, and the availability of the CCGs as aspects they were satisfied with. It was mainly the attitude of staff at some formal health services and the dearth of medication and supplies that were needed that PWAs complained about. In general they required poverty relief, jobs which they could still manage, and greater involvement in the prevention and care 
aspects of the epidemic.

In terms of the quality of palliative care rendered by the CCGs, it would seem that this was very high. Many of the PWAs reported that the care enhanced their self-respect and ability to cope. They told stories of how their physical status improved, and how the CCGs dealt with psychosocial problems.

When interpreting the results, it has to be remembered that consumers are often not very critical if they know they have no option but to use the service, but the fact that they were more critical of some components than of others raises the hope that they were expressing their real feelings.

\section{Carers of PWAs:}

The home carers interviewed in groups or individually were also universally appreciative of the information, assistance and support received. They particularly mentioned the resources brought to them and the access to a vehicle, but the emotional support was also much appreciated. Professionals rated this aspect of the project highly.

Problems experienced centred around the acceptance of the client by the family, which sometimes took some time. The lack of resources for the families to care for the client, even in terms of such basics as food, was a further problem, which the model was not equipped to deal with adequately. Finally, some clients came into the system at such a late stage that it left inadequate time to prepare the carers for the terminal phases of the care and for the future.

\section{CCGs}

CCGs were generally very satisfied with their support, and this satisfaction was shared by the professionals in the partnership. The hospice team were the main supporters, but the clinic staff, the peer group and the community were also seen as playing a role. In the two settings where there were problems, the language barrier and the lack of a dedicated supervisor with adequate back-up were the problems.

The concept of supervision is not well developed in the health services of South Africa. It is mainly used in terms of management supervision, and not clinical supervision. Only social workers and clinical psychologists routinely make use of clinical supervision in the sense that it is a professional requirement that a practitioner in private practice has to have a supervisor. There is growing recognition internationally that the process of regular and systematic supervision can play an important role in ensuring quality of care (National Health Services Executive, 1995). If that is true in the case of fully trained professionals, it is even more important in the case of health workers with limited training.

In a study in the Solomon Islands it was found that most CCGs dropped out because of their pay being inadequate or irregular (38\%), while a large number dropped out because of a lack of community support (32\%) (Chevalier, Lapo, O'Brien and Wierzba, 1993). While there do not seem to be similar problems in the projects surveyed, in one site CCGs mentioned their very low payment for a difficult job. It is important not to ex- ploit this very vulnerable resource.

\section{What was the effect on the partners?}

The effect on all three major services was mixed. On the positive side they have become more involved with the HIV/AIDS problem, have been gratified by the service they were able to render, and have seen a decrease in inappropriate use of services such as hospitals. On the negative side, the service demands have increased greatly, and many of the activities have taken more time than anticipated. The increased level of networking mentioned above also had a positive impact on all partners.

The level of involvement of clinics in the project needs to be highlighted. In many sites CCGs start their days at the clinics, set priorities for their work with clinic staff and work closely with them. For many clinics this has been their first experience of working with NGO staff based in their communities, and the contact has been enriching for both parties.

In contrast to this relatively positive picture, Cabral (1993) paints a dim picture of the impact on hospitals of an uncontrolled HIV/AIDS epidemic with inadequate planning and management. He foresees congested hospitals, competition between essential services to be rendered at clinics and increased strain on staff. None of these effects were seen at the seven sites under study.

It was not possible to make any specific comments in this study on HIV/AIDS bed occupancy, since no such statistics are kept or could be accessed. Patients are not generally tested, and could not be tested for this study.

With regard to the impact on PWAs and their carers, there is no doubt that the model gives hope and dignity to the PWA and essential support to their carers. But it may go further than that. The issue of disclosure is a recurring theme in the AIDS literature. In a recent editorial in the Sunday Times, Msomi (2000: 18) writes eloquently of the "terrible assassin" stalking the youth. He describes the funeral of a once popular young teacher where it was difficult to find enough pall bearers because people suspected that the man had died of AIDS. He also describes a funeral where the older brother of the deceased woman disclosed her status at her funeral, to the horror of other family members and friends. He ends by saying "I wonder how many deaths it will take for this community to begin openly talking about AIDS". It is indeed difficult to see how a community can respond adequately to an enemy they keep on denying.

The project may have the kernel of the solution to this problem. In many cases one could see the acceptance spreading: first the client would accept his/her status, and then decide to disclose to the family. Once the family had accepted it, friends or church associates were sometimes involved. Surely this ground-level acceptance can be nurtured and made to grow in opposition to the denial and rejection which still reigns in most communities. 


\section{Recommendations}

1. With regard to the implementation of the model there seems to be enough evidence of the contribution the model has made to recommend that it be implemented more widely. Whether this implementation should continue to centre around the hospice as main NGO is dependent on the capacity of this NGO and others in communities across the country. It might be best for each province to commence by building projects around the major NGOs who already have the management capacity to lead such projects. District hospitals can also be used if no such NGOs are available. Once the model has been implemented more generally, these strong centres can be used to support settings where such management capacity does not exist.

2. It would also seem that poverty relief moneys could be used to pay CCGs. These people often represent the poorest communities, and the poorest of these commnities (the women). By training them and paying them to do this crucial job, they would be given the privilege of a paid job, while the community's need for home-based care is served at the same time.

With regard to further research it is recommended that:

1. A comparative study should be done to compare the utilization of services in sites where the model has been implemented, with those in which it has not been implemented. There is no other way to answer a number of questions with regard to the efficacy of the model in decreasing hospitalization rates.

2. Further studies should be done to explore the possibility of integrating home-based care with other activities of community health workers, such as Directly Observed treatment for Tuberculosis (DOT). If the model is to be generalized to other communities, it is clearly not ideal that the same patient be visited by more than one community health worker. However, it is not clear how such a comprehensive worker will fit into this model.

3. Further intensive research is necessary to explore the relationship between the implementation of this model and the prevention of HIV/AIDS. The premise that the acceptance of HIV/AIDS engendered by home-based care can lead to more openness about the illness in the micro-community, and this in turn can influence sexual behaviour, needs to be tested.

\section{Conclusion}

There seem to be consensus amongst providers and consumers that the model addresses the needs of PWAs and their carers, that it can be replicated, and that it has made a major contribution to making the problems in HIV/AIDS care more visible, and uniting a range of partners in dealing with the threat it poses. These is also consensus that the two main problems inadequately addressed are poverty alleviation and the care of orphans. Problems with implementation are the engagement of all partners, the continued stigmatization and matching of resources with needs.

It is perhaps best to conclude by quoting a CCG:

This project must continue. It has made me an understanding person, and in our community it has made these people (with AIDS) people who are looked after.

\section{References}

CABRAL, J R 1993: AIDS in Africa: can the hospitals cope? Health Policy and Planning. 8(2): 157-160.

CHEVALIER, C; LAPO, A; O'BRIEN, J \& WIERZBA, TF 1993: Why village health workers drop out. World Health Forum. 14: 258-261.

CRABTREE, BF \& WILLIAM, WL 1992: Doing qualitative research. Newbury Park: Sage Publications.

DEPARTMENT OF HEALTH 2000: HIV/AIDS Strategic plan for South Africa. Pretoria: Department of Health.

DOYLE, J; HANKS, GW \& MACDONALD, N 1993: Oxford Textbook of Palliative Medicine. Oxford: Oxford University Press.

EDITOR 1994: Inter-sectoral action for health: making it work. Health Promotion International. 9(3): 143-144.

LOUDEN, M 1999: South Coast Hospice's Community-Based HIV/AIDS Home-Care Model. HIV/AIDS Best Practice Series, Pretoria: Department of Health.

MSOMI, ST 2000: A terrible new assassin stalks the youth. Sunday Times. June 18. 2000: 18.

NATIONAL HEALTH SERVICES EXECUTIVE 1995: Clinical supervision: conference organized by the NHS Executive of the UK . Journal of Advanced Nursing. 21: 1029-1031

PATTON, MQ 1978: Utilization-focused evaluation, $2^{\text {nd }}$ Edition. Beverly Hills: Sage Publications.

SCHRETTENBRUNNER, A \& HARPHAM, T 1993: A different approach to evaluating PHC projects in developing countries: how acceptable is it to aid agencies? Health Policy and Planning. 8(2): 128-135.

THOMPSON, PR \& STACHENKO, S 1994: Building and mobilizing partnerships for health: a national strategy. Health Promotion International. 9(3): 211-214. 